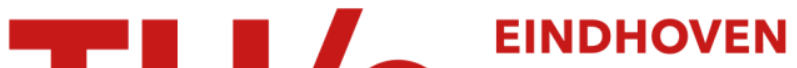 \\ UNIVERSITY OF \\ TECHNOLOGY
}

\section{Vacuum circuit breaker current-zero phenomena}

Citation for published version (APA):

Lanen, van, E. P. A., Popov, M., Sluis, van der, L., \& Smeets, R. P. P. (2005). Vacuum circuit breaker currentzero phenomena. IEEE Transactions on Plasma Science, 33(5), 1589-1593.

https://doi.org/10.1109/TPS.2005.856486

DOI:

10.1109/TPS.2005.856486

Document status and date:

Published: 01/01/2005

Document Version:

Publisher's PDF, also known as Version of Record (includes final page, issue and volume numbers)

Please check the document version of this publication:

- A submitted manuscript is the version of the article upon submission and before peer-review. There can be important differences between the submitted version and the official published version of record. People interested in the research are advised to contact the author for the final version of the publication, or visit the $\mathrm{DOI}$ to the publisher's website.

- The final author version and the galley proof are versions of the publication after peer review.

- The final published version features the final layout of the paper including the volume, issue and page numbers.

Link to publication

\section{General rights}

Copyright and moral rights for the publications made accessible in the public portal are retained by the authors and/or other copyright owners and it is a condition of accessing publications that users recognise and abide by the legal requirements associated with these rights.

- Users may download and print one copy of any publication from the public portal for the purpose of private study or research.

- You may not further distribute the material or use it for any profit-making activity or commercial gain

- You may freely distribute the URL identifying the publication in the public portal.

If the publication is distributed under the terms of Article $25 \mathrm{fa}$ of the Dutch Copyright Act, indicated by the "Taverne" license above, please follow below link for the End User Agreement:

www.tue.nl/taverne

Take down policy

If you believe that this document breaches copyright please contact us at:

openaccess@tue.nl

providing details and we will investigate your claim. 


\title{
Vacuum Circuit Breaker Current-Zero Phenomena
}

\author{
Ezra P. A. van Lanen, Member, IEEE, Marjan Popov, Senior Member, IEEE, Lou van der Sluis, Senior Member, IEEE, \\ and René P. P. Smeets, Senior Member, IEEE
}

\begin{abstract}
Post-arc current phenomena that occur when interrupting high currents with vacuum circuit breakers have been investigated. High resolution measuring equipment has been used to measure both the post-arc current and the arc voltage in the current-zero region. Three examples of frequently observed phenomena are described. The first describes the phenomenon that in the event of a current-chopping, the current is zero for a short period of time just before the natural alternating current zero, but continues to flow afterwards, in the form of a post-arc current. The second and third example deal with the post-arc phenomena after currents that are much higher than the test breaker's rated short-circuit current. These examples show a low-voltage period after current-zero. Apparently, during this post-arc period, the residual plasma between the breaker's contacts conduct well. In addition to the voltage-zero period, the voltage trace in the third example also shows evidence of current-chopping. This means that the plasma conducts poorly just before current-zero, but conducts well immediately afterwards. The post-arc current model of Andrews and Varey is verified with measurements.
\end{abstract}

Index Terms-Current chopping, short circuit currents, vacuum arcs, vacuum circuit breakers.

\section{INTRODUCTION}

W HEN A vacuum circuit breaker (VCB) interrupts a current, the current continues to flow a short moment after current zero. This post-arc current is a result of the residual plasma that exists between the breaker's contacts and is swept away under the influence of a transient recovery voltage (TRV). Many of the post-arc current characteristics relate to the breaker's properties, such as the geometry, the contact material, and the degree of the vacuum. For this reason, it is believed that the post-arc current might indicate the breaker's performance, and it has been subject to investigation for many years [1]-[7].

This paper presents new results obtained from short-circuit measurements. For this purpose, highly detailed measurements are performed on a commercially available VCB. Three events that frequently return in measurements are described hereafter, which show particular behavior in the conductance of the plasma near current zero. In the first case, the current instantly drops to zero just before the natural current-zero, but despite this pre-zero current quenching, a post-arc current flows when the voltage across the breaker commutates. In contrast to the

Manuscript received December 31, 2004; revised May 9, 2005. This work was supported by the Dutch Technology Foundation STW under Grant DCS.5975.

E. P. A. van Lanen, M. Popov, and L. van der Sluis are with the Electrical Power System Laboratory (EPS), Faculty of Electrical Engineering, Mathematics and Computer Science, Delft University of Technology, 2600 GA Delft, The Netherlands (e-mail: e.p.a.vanlanen@ewi.tudelft.nl).

R. P. P. Smeets is with the KEMA High-Power Laboratory, 6800 ET Arnhem, The Netherlands and also with the Eindhoven University of Technology, 5600 MB Eindhoven, The Netherlands.

Digital Object Identifier 10.1109/TPS.2005.856486

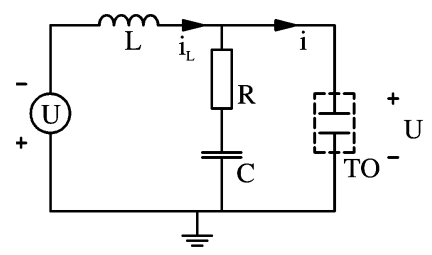

Fig. 1. Simplified test circuit for performing current-zero measurements.

poor conductivity conditions of the plasma in the first event, the second shows a very good (residual) plasma conductance for a short period of time after current-zero. This is demonstrated by a low-voltage period lasting up to $1 \mu$ s after current-zero, and a current of which its slope remains nearly constant during this period. This is observed in tests with a current much higher than the breaker's rated short-circuit current.

The third case gives a demonstration of the events of both the first and the second case. An overvoltage just before currentzero provides the indirect evidence of a current chop after a very high current, but the low-voltage period as described before is also measured. This clearly demonstrates the instability of the arc near current zero, as the conductive properties of the plasma just before the natural current-zero deteriorate even though they appear sound just after current-zero.

Another way of investigating the post-arc behavior is by simulating the breaker's behavior. However, due to the complicated physical processes in the vacuum chamber, both during arcing and after current-zero, the development of a model that simulates the breaker's behavior properly is rather elaborate. A commonly used model for the post-arc current is used [8]-[13] and its validity investigated.

\section{MeAsurement Setup}

Different test circuits were used for the short-circuit measurements. A generalized version of these test-circuits is shown in Fig. 1. Initially, a current flows through the inductance $L$ and a metal vapor arc in the breaker (TO) in the indicated direction. After current zero, the arc disappears, and the residual plasma between the contacts of the breaker is cleared by a TRV.

The current and voltage are measured by a Rogowski coil and a high-frequency ohmic voltage divider, respectively, in combination with transient recorders with 12-bit resolution and a sampling frequency of $40 \mathrm{MHz}$ [14]. The measuring system is specifically designed to measure low values of voltages and currents in electrically polluted areas, such as a test laboratory.

For the test object, we used a commercially available VCB which has axial magnetic field contacts, a rated voltage of $24 \mathrm{kV}$, and a rated short-circuit current of $20 \mathrm{kA}$ with $35 \%$ direct current (dc) asymmetry. 


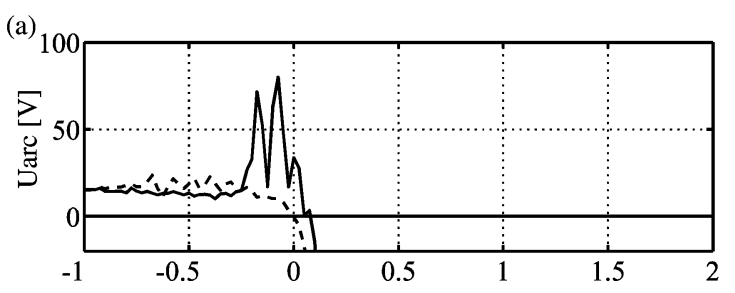

(b)

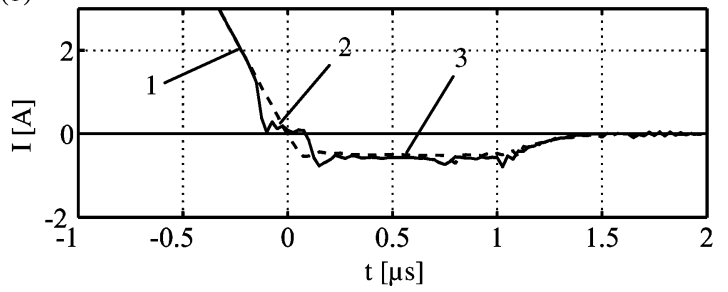

Fig. 2. (a) Arc voltage and (b) post-arc current after a smooth current decline (dashed lines) and after a current chop (solid line). In both measurements, a peak-arc current of $39 \mathrm{kA}$ and an arcing time of $3.4 \mathrm{~ms}$ were used.

\section{Post-Arc Current After Current Chopping}

When the arc current in a circuit breaker declines toward zero, the instability of the arc causes current interruption before the natural current zero. This phenomenon is known as current chopping, and the level at which the current spontaneously drops to zero is called chopping current. Although current chopping occurs in all types of circuit breakers [15]-[17], the chopping current of vacuum arcs is in general higher than in other types of breakers.

Due to the potential hazard of overvoltages caused by trapped magnetical energy in the load after current chopping, this phenomena has been thoroughly investigated. Manufacturers have expended considerable effort to reduce the chopping current in VCBs in the past 20 years [18]-[20].

A clear example of such a chopping event is depicted in Fig. 2. Shown here are two out of five measurements performed with equal settings. The dashed trace shows an interruption without current chopping, whereas the solid trace shows a current chopping event. In both measurements, the $50-\mathrm{Hz}$ peak arc current reached a value of $39 \mathrm{kA}$, and the breaker was opened $3.4 \mathrm{~ms}$ before current-zero.

The chopping current in Fig. 2 is approximately 1 A. Due to the setup of the test circuit, at the moment of chopping, this current should instantly flow through the resistance-capacitance $(R C)$ branch (see Fig. 1). Since the resistance $R$ in this circuit was $135 \Omega$, theoretically, the peak value of the overvoltage $U$ should be at least $135 \mathrm{~V}$. However, the measured overvoltage is not even half this value. The most probable explanation for the difference between the theoretical and observed value is that the current does not drop to zero instantly but declines to zero with a certain slope.

Moreover, stray capacitances and inductances surrounding the breaker, which are not included in Fig. 1, might also suppress the overvoltage. It is well known that capacitances parallel to VCBs increase the chopping current [15], [17], [21].

Another apparently contradictory event here is that the current interrupts before natural current-zero but continues to flow afterwards. This indicates that the breaker has a diode-like a)
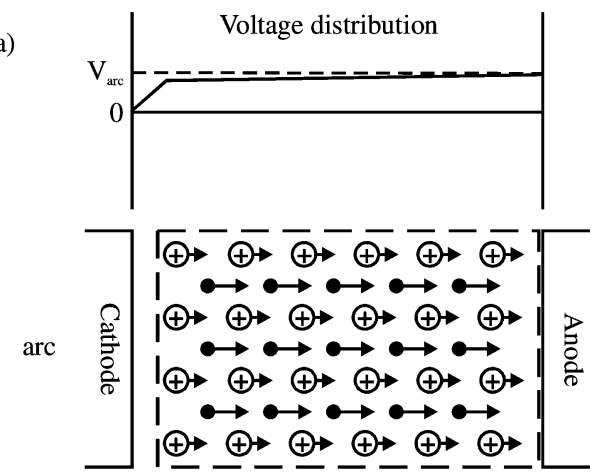

b)
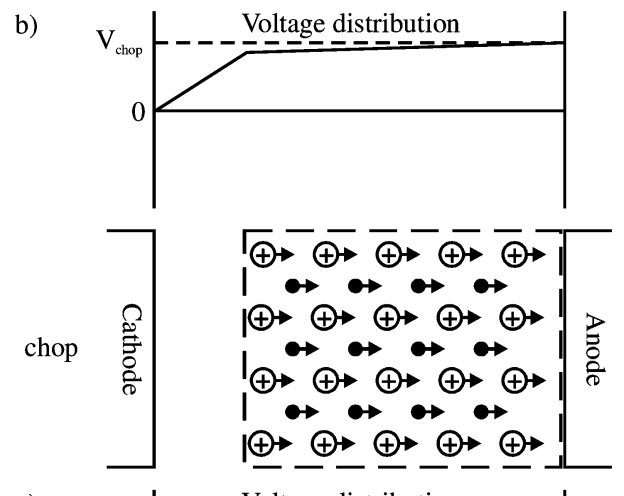

c)
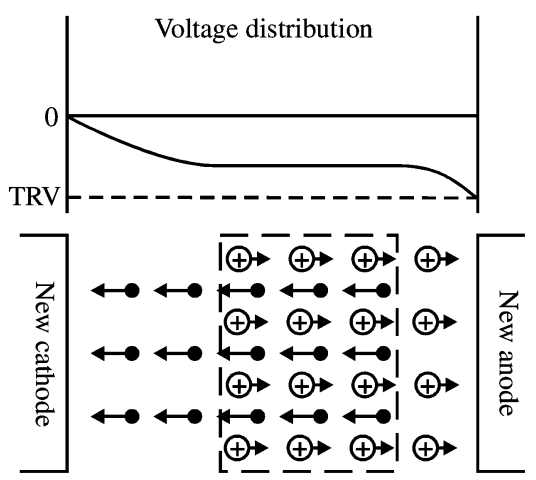

Fig. 3. Schematic representation of the movement of charged particles between the contacts of a VCB near current zero. Instants (a)-(c) correspond to the numbers 1-3 in Fig. 2(b). Dashed boxes indicate a quasi-neutral zone.

behavior immediately after current-chopping. In addition, the post-arc current after chopping strongly resembles the post-arc current of a natural current interruption.

We believe that this behavior can be explained with an addition to the accepted theory about post-arc currents [1], [9]. When the VCB's contacts open, the current continues to flow through a metal vapor arc. The partly ionised vapor arises from cathode spots; tiny hot spots on the cathode. Due to the large pressure gradient near these cathode spots, the majority of particles is launched toward the anode [see Fig. 3(a)]. The high conductivity of the plasma indicates that the interelectrode space is essentially field-free, and an almost equal amount of charge is present inside the gap at all times. The current of the anode-directed ion stream is approximately $10 \%$ of the total discharge current [20], [22], and the mean velocity of ions can reach a value of up to $10^{4} \mathrm{~m} / \mathrm{s}$ [6], [7], [15]. This counter current of the ions is compensated by the flow of faster moving electrons, and as a result of the low electric field here, ions are hardly influenced by the opposing electric force. The largest part of the 
arc voltage is taken up by the region near the cathode where the cathode spots are active.

When the final cathode spot extinguishes just before the natural current zero in the case of a current chop, the supply of charge to the plasma is interrupted instantaneously. Due to their inertia, the ions continue to move toward the anode with their original velocity. Within the time frame of this event, it is assumed that the electrons, which have a much smaller inertia than the ions, instantly adapt to a change in the electric field. That means that they compensate the ion current by moving with the same speed and in the same direction as the ions. During this process, positive and negative charge arrives in the same quantity and velocity at the anode and no charge arrives at the cathode. Although ions and electrons move inside the gap, the net charge flow is zero which means that the electrical current is zero.

In fact, the entire quasi-neutral plasma moves toward the anode, leaving an evacuated sheath in front of the cathode. Despite the breaker's low conductivity at this point, the conductivity of the plasma is still very high, and, therefore, the overvoltage is mainly taken up by the sheath [see Fig. 3(b)].

When the voltage commutates, the electric field inside the inter-electrode gap forces the electrons to reverse. Apart from the ion-depleted zone in front of the post-arc anode, the theory on post-arc currents in vacuum apply to this system. While the ions continue to move toward the post-arc cathode due to their inertia, the electrons reverse under the influence of the reversed electrical field [see Fig. 3(c)]. This results in a net flow of charge again, which is observed in Fig. 2(b).

\section{Low-Voltage Period After High-CurRent INTERRUPTION}

A number of tests were carried out with a level of decaying current asymmetry having a dc component (for asymmetrical testing, see e.g., [23] and [24]). The result is a current trace with major and minor loops. At $24 \mathrm{kA}$, the applied alternating current (ac) was larger than the breaker's rated short-circuit current and as a result, in almost all the test the breaker failed to interrupt after the first (major) current loop, but succeeded to quench the current at a following current-zero. However, the low values and the smooth state of the arc voltage observed in the measurements indicate that the arc did not constrict to form an anode spot, but remained diffuse during all our tests.

Fig. 4 shows a current-zero measurement after the first interruption attempt. The voltage in this figure displays a distinctive behavior from other current-zero events; it remains almost zero for about $1 \mu \mathrm{s}$ after current-zero.

This effect can partly be explained with the aid of an existing theory on post-arc currents [9]: after current-zero, electrons are still moving into the same direction as the ions, but decelerate and eventually reverse at a certain current level. After this moment, the electrons are extracted from the plasma, leaving a positively charged ion-sheath in front of the cathode, like in Fig. 3(c). However, because all cathode spots have already disappeared before current zero, there is no mechanism to exchange charge between the new anode and the plasma. Hence, an evacuated gap should form in front of the new anode,

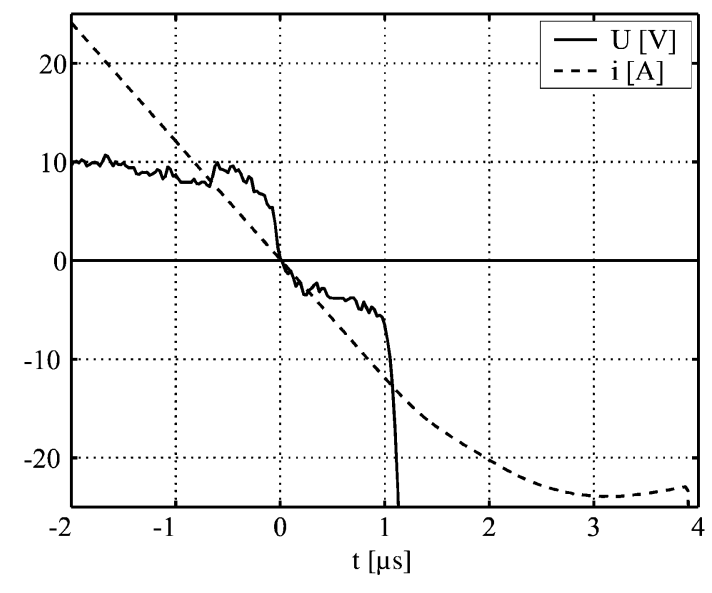

Fig. 4. Current-zero measurement after a high-current arc. Voltage remains very low for $1 \mu \mathrm{s}$ after current-zero.

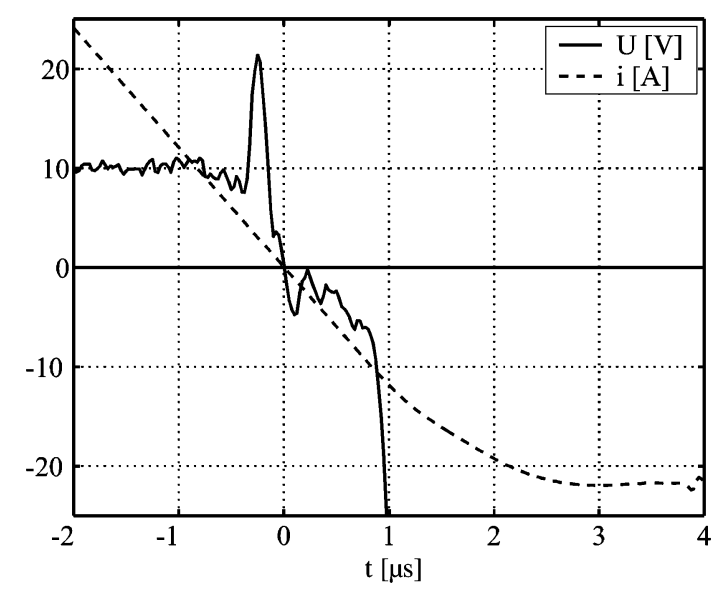

Fig. 5. Measured current chop after a high-current arc.

similar to the situation depicted in Fig. 3(b), yielding a low conductivity. In that case, the current should be zero and the TRV should start to rise immediately after current zero.

Apparently, there are other physical processes active which have not been accounted for. For example, the presented theory omits the generation of new charge carriers by means of ionization due to collisions of high-energy ions and electrons with each other, with walls or with neutral particles inside the gap [3], [25].

\section{Current Chopping at High-CURRENT InTERruption}

Current chopping is the result of the vacuum arc instability. At steeper current slopes near current zero, following after a high-peak arc current, the average instantaneous current is larger, and hence, the arc remains in an unstable situation for less time, decreasing the probability of current chopping [17]. The result in Fig. 5 clearly demonstrates the low value of current chopping after a high current loop where the same setup has been used as in Section IV.

Although the actual chopping of the current is not visible in this figure (the chopping current is about $0.2 \mathrm{~A}$ ), its presence can be deduced from the overvoltage just before current zero. 

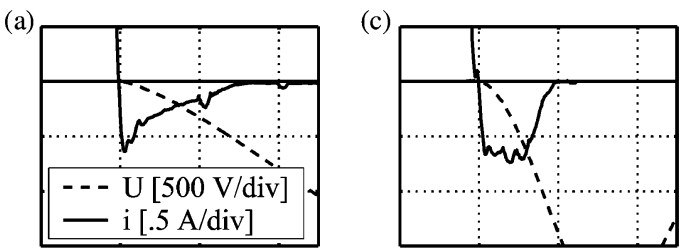

(b)

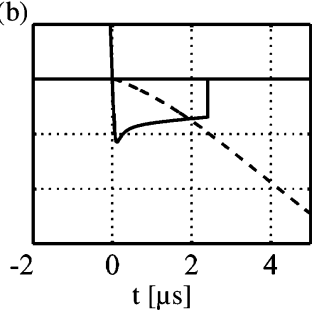

(d)

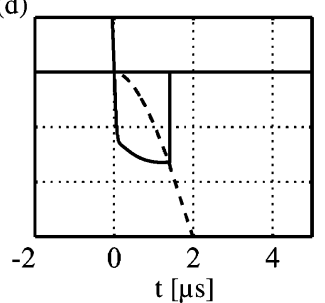

Fig. 6. (a) Measurement and (b) simulation results with a capacitance of $10 \mathrm{nF}$ Plots in (c) and (d) correspond to those in (a) and (b), respectively, except that now a capacitance of $1 \mathrm{nF}$ is used. Second zero-crossing in (c) is the result of the influence of a stray capacitance, parallel to the test object.

Again, a post-arc current flows after current chopping, which means that the theory of Section III partly applies to this measurement as well. However, the low-voltage period lasting $1 \mu \mathrm{s}$ after current zero in this measurement indicates, just as in Section IV, that the actual physical processes are more complicated than the theory presented in Section III.

\section{Modelling of CurRent-Zero Events}

The theory of an ion-sheath growing in front of the cathode is often used to model the post-arc current. This theory relates the sheath thickness, the post-arc current, and the TRV, by means of Child's law, the Ion-Matrix model, or the Continuous Transaction model of Andrews and Varey [2], [9], [10], [26]. Although these models are based on assumptions that do not always apply to the situation after a VCB short-circuit interruption, they can be used for specific, low post-arc current investigation.

Fig. 6 shows the simulation of post-arc currents, modeled with the theory of Andrews and Varey, compared with measured data. Two separate simulations are shown, with equal VCBmodel parameters, but a different capacitor $C$ (see Fig. 1). Some of the parameters were estimated, which is in accordance with the literature (e.g., the initial ion density inside the gap and the ion density decay), while others were derived from the breaker's characteristics (e.g., the contact diameter and the separation between the contacts at current-zero).

In the model, the post-arc current is immediately interrupted when the ion-sheath reaches the anode. This explains the sharp drop to zero in the simulations around $2 \mu$ s after current-zero. Contrary to this, the measurements show a smooth decay toward zero. One reason for this difference is because in the model, it is assumed that there is a sharp boundary between the sheath and the plasma, and that the sheath is electron-free. In the actual situation, this is probably some sort of smooth transition from the sheath to the plasma. Moreover, the model uses the assumption that all ions flow toward the anode with the same speed and direction. According to the measurements described in literature, this assumption is not quite valid; the ion velocity, and its direction, is expressed in a distribution function.

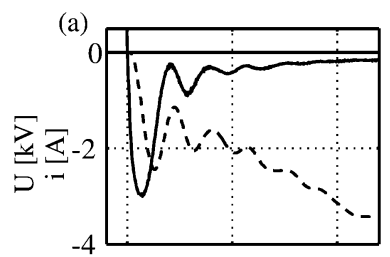

(c)
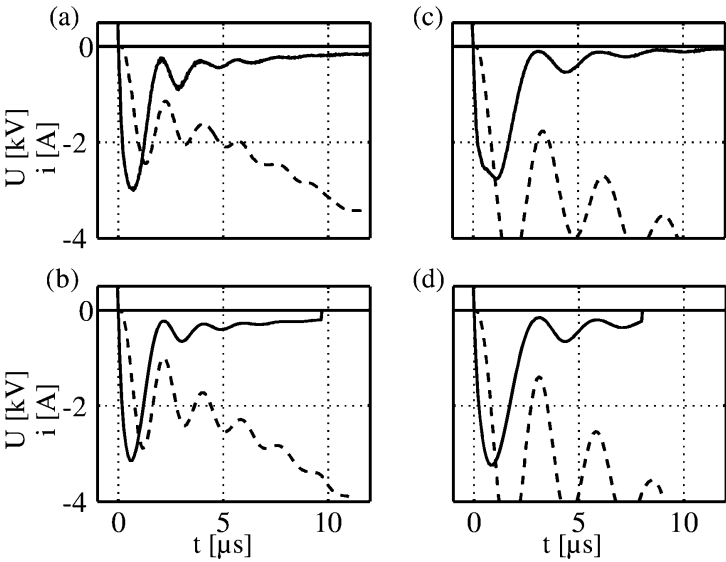

(d)

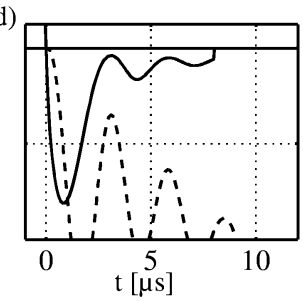

Fig. 7. (a) Measurement and (b) simulation results with an inductance $L_{2}$ of $105 \mu \mathrm{H}$. Plots in (c) and (d) correspond to those in (a) and (b), except that now an inductance $L_{2}$ of $225 \mu \mathrm{H}$ is used.

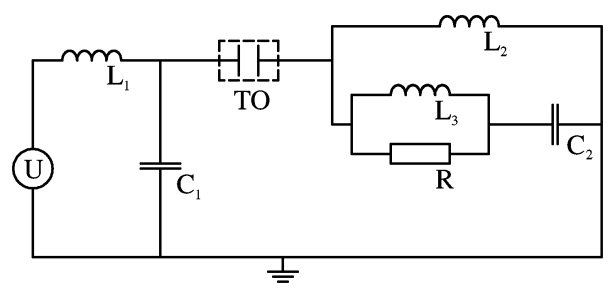

Fig. 8. Short-Line Fault measuring circuit.

Nevertheless, despite the relatively high level of noise present on the measured signals, there are some clear similarities between the measurements and simulations. Apparently, at these levels of post-arc current, simulation of the breaker's behavior by means of the theory of Andrews and Varey is valid.

In Fig. 7, another post-arc current simulation is presented. The measurements in this example were performed with a Short-Line Fault simulation circuit [14], which is shown in Fig. 8. Here, the same approach to model the post-arc current has been used as in the previous example, but now the post-arc currents reach a much higher value, and instead of $C\left(C_{1}\right.$ in Fig. 8), $L_{2}$ was altered.

In the case of Fig. 7(a) and (b), there is still a strong similarity between the simulation and the measurement, but this does not count for Fig. 7(c) and (d). Here, the first peak in the measured post-arc current shows a different shape, compared to that of the simulated post-arc current. Apparently, the model assumptions do not hold and it cannot be used to describe this measurement.

\section{CONCLUSION}

Detailed measurements of post-arc currents after interruption of high currents have been performed. Three frequently observed phenomena in the measurements are described. These are the post-arc current flowing after current-chopping, a voltagezero period after the interruption of a high short-circuit current, and the combination of these two observations. The post-arc current flowing after current chopping can be explained by observing the net flow of charged particles between the contacts of a VCB. However, the low-voltage period just after current-zero at very high short-circuit tests requires a more elaborate physical description. 
For a further investigation of the post-arc behavior of VCBs, the results of a theoretical post-arc current model were compared with measured data. It has been shown that this model is valid for only a small range of measurements.

\section{ACKNOWLEDGMENT}

The authors would like to thank Eaton Electric for providing us the test objects, and KEMA for giving us the use of their measuring equipment and their test laboratory.

\section{REFERENCES}

[1] R. Holmes and S. Yanabu, "Post-arc current mechanism in vacuum interrupters," J. Phys. D, Appl. Phys., vol. 6, pp. 1217-1231, 1973.

[2] S. Yanabu, M. Homma, E. Kaneko, and T. Tamagawa, "Post arc current of vacuum interrupters," IEEE Trans. Power App. Syst., vol. PAS-104, pp. 166-172, Jan. 1985.

[3] E. Dullni, E. Schade, and B. Gellert, "Dielectric recovery of vacuum arcs after strong anode spot activity," presented at the XIIth ISDEIV, Shoresh, Israel, 1986.

[4] R. Gebel, "Vapor shield potential in vacuum interrupters after clearing of short circuits," IEEE Trans. Plasma Sci., vol. 17, no. 5, pp. 834-838, Oct. 1989.

[5] H. Pursch and B. Jüttner, "The behavior of the ion current at the extinction of high current vacuum arcs," in XVIIth ISDEIV, Berkeley, CA, 1996.

[6] G. Düning and M. Lindmayer, "Energy and density of ions in vacuum arcs between axial and radial magnetic field contacts," IEEE Trans. Plasma Sci., vol. 29, no. 5, pp. 726-733, Oct. 2001.

[7] C. Rusteberg, "Bestimmung von plasma-parametern in vakuumhochstrombögen," Ph.D. dissertation, Tech. Univ. Braunschweig, Braunschweig, Germany, 1994.

[8] M. T. Glinkowski and P. Stoving, "Numerical modeling of vacuum arc interruption based on the simplified plasma equations," IEEE Trans. Magn., vol. 31, no. 10, pp. 1924-1927, May 1995.

[9] J. G. Andrews and R. H. Varey, "Sheath growth in a low pressure plasma," Phys. Fluids, vol. 14, no. 2, pp. 339-343, Feb. 1971

[10] J. Kaumanns, "Measurements and modeling in the current zero region of vacuum circuit breakers for high current interruption," IEEE Trans. Plasma Sci., vol. 25, no. 4, pp. 632-636, Aug. 1997.

[11] M. Lindmayer and E.-D. Wilkening, "Breakdown of short vacuum gaps after current zero of high frequency arcs," presented at the XIVth ISDEIV, Santa Fe, NM, 1990.

[12] E. F. J. Huber, K. D. Weltmann, and K. Froehlich, "Influence of interrupted current amplitude on the post-arc current and gap recovery after current zero-Experiment and simulation," IEEE Trans. Plasma Sci., vol. 27, no. 4, pp. 930-937, Aug. 1999.

[13] K. Steinke, M. Lindmayer, and K.-D. Weltmann, "Post-arc currents of vacuum interrupters with axial magnetic field contacts under high curent and voltage stress," presented at the XIXth ISDEIV, Xi'an, China, 2000.

[14] R. P. P. Smeets and W. A. van der Linden, "Current-zero measurements of vacuum circuit breakers interrupting short-line faults," IEEE Trans. Plasma Sci., vol. 31, no. 5, pp. 852-858, Oct. 2003.

[15] G. A. Farrall, "Current zero phenomena," in Vacuum Arcs, Theory and Application, J. M. Lafferty, Ed. New York: Wiley, 1980.

[16] S. Stewart, Distribution Switchgear. London, U.K.: IEE, 2004, pp. 77-77.

[17] J. D. Gibbs, D. Koch, P. Malkin, and K. J. Cornick, "Investigations of prestriking and current chopping in medium voltage sf6 rotating arc and vacuum switchgear," IEEE Trans. Power Del., vol. 4, pp. 308-316, Jan. 1989.

[18] M. Popov, "Switching three-phase distribution transformers with a vacuum circuit breaker," Ph.D. disseration, Delft Univ. Technol., Delft, The Netherlands, 2002.

[19] R. P. P. Smeets, "Low-current behavior and current chopping of vacuum arcs," Ph.D. dissertation, Eindhoven Univ. Technol., Eindhoven, The Netherlands, 1987.

[20] A. Greenwood, Vacuum Switchgear. London, U.K.: IEE, 1994.

[21] C. Ding and S. Yanabu, "Effect of parallel circuit parameters on the instability of a low-current vacuum arc," IEEE Trans. Plasma Sci., vol. 31, no. 5 , pp. $877-883$, Oct. 2003.

[22] M. T. Glinkowski, "Behavior of vacuum switching devices for short gaps," Ph.D. dissertation, Rensselaer Polytech. Inst., Troy, NY, 1989.
[23] M. B. J. Leusenkamp, "Vacuum interrupter model based on breaking tests," IEEE Trans. Plasma Sci., vol. 27, no. 5, pp. 969-976, Aug. 1999.

[24] S. Stewart, Distribution Switchgear. London, U.K.: IEE, 2004.

[25] E. Schade and E. Dullni, "The characteristic features of recovery of the breakdown strength of vacuum switching devices after interruption of high currents," in XIXth ISDEIV, Xi' an, China, 2000.

[26] M. Glinkowski and A. Greenwood, "Computer simulation of post-arc plasma behavior at short contact separation in vacuum," IEEE Trans. Plasma Sci., vol. 17, no. 1, pp. 45-50, Feb. 1989.

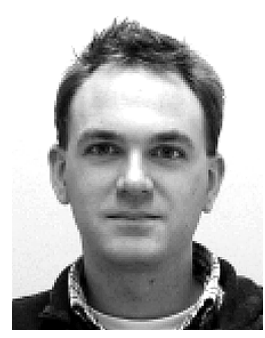

Ezra P. A. van Lanen (M'03) was born in Eindhoven, The Netherlands, on February 6, 1975. He received the M.Sc. degree in electrical engineering, from the Delft University of Technology, Delft, The Netherlands, in 2002, where he is currently working toward the $\mathrm{Ph}$.D. degree on digital testing of vacuum circuit breakers.

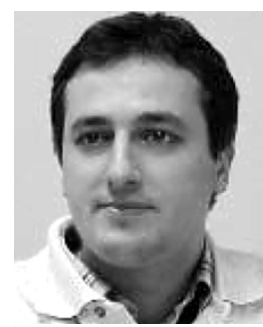

Marjan Popov (M'95-SM'03) received the Dipl.-Ing. and M.S. degrees in electrical engineering from the Sts. Cyril and Methodius University, Skopje, Macedonia, in 1993 and 1998, respectively, and the Ph.D. degree from the Delft University of Technology, Delft, The Netherlands, in 2002.

From 1993 until 1998, he was a Teaching and Research Assistant with the Faculty of Electrical Engineering, University of Skopje. In 1997, he was an Academic Visitor at the University of Liverpool, Liverpool, U.K. Currently, he is with the Power System Laboratory, Delft University of Technology, Delft, The Netherlands, where he is an Assistant Professor in the Electrical Power Systems Laboratory. His major fields of interest are arc modeling, transients in power systems, parameter estimation, and relay protection.

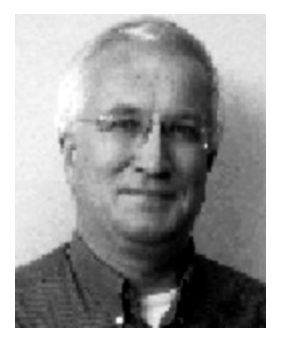

Lou van der Sluis (M'82-SM'86) was born in Geervliet, The Netherlands, on July 10, 1950. He received the M.Sc. degree in electrical engineering from the Delft University of Technology, Delft, The Netherlands, in 1974

He joined the KEMA High Power Laboratory, Arnhem, The Netherlands, in 1977 as a Test Engineer and was involved in the development of a data acquisition system for the High Power Laboratory, computer calculations of test circuits, and the analysis of test data by digital computer. In 1990, he became a Part-Time Professor, and since 1992, he has been employed as a Full-Time Professor in the Power Systems Laboratory, Delft University of Technology.

Prof. van der Sluis is a past Chairman of CC- 03 of Cigre and Cired to study the transient recovery voltages in medium- and high-voltage networks.

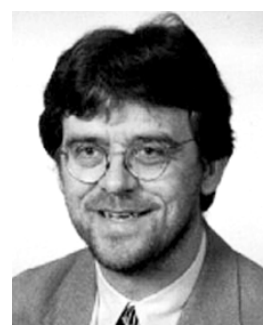

René P. P. Smeets (M'95-SM'02) received the M.Sc. degree in physics from the Eindhoven University of Technology, Eindhoven, The Netherlands, in 1981, and the Ph.D. degree for research work on vacuum arcs from Eindhoven University, Eindhoven, The Netherlands, in 1987.

Until 1995, he was an Assistant Professor with Eindhoven University. During 1991, he was with the Heavy Apparatus Engineering Laboratory, Toshiba Corporation, Kawasaki, Japan. In 1995, he joined KEMA, Arnhem, The Netherlands. At present, he manages the research and development activities of the High-Power Laboratory, KEMA. In 2001, he was appointed Part-Time Professor at Eindhoven University of Technology. 